\title{
Application of ANFIS for the Estimation of Queuing in a Postal Network Unit: A Case Study
}

\author{
Bojan Jovanović ${ }^{1}$, Tatjana Grbić ${ }^{1}$, Nebojša Bojović ${ }^{2}$, Momčilo \\ Kujačić ${ }^{1}$, Dragana Šarac ${ }^{1}$ \\ ${ }^{1}$ University of Novi Sad, Faculty of Technical Sciences \\ Trg Dositeja Obradovića 6, 21000 Novi Sad, Serbia \\ bojanjov@uns.ac.rs, tatjana@uns.ac.rs,kujacic@uns.ac.rs, dsarac@uns.ac.rs \\ ${ }^{2}$ University of Belgrade, Faculty of Transport and Traffic Engineering \\ Vojvode Stepe 305, 11000 Belgrade, Serbia \\ nb.bojovic@sf.bg.ac.rs
}

\begin{abstract}
Regardless the level of technological development in a community, the unavoidable phenomenon is the appearance of queuing. This situation will continue as long as there is the customer's need for the direct contact with the service suppliers, as the case is in the Post of Serbia. The aim of the paper is to estimate the time a customer will spend in queuing while approaching the counter for financial services in a postal network unit. The observed system comprises a single queue, three handling channels and the service according to the FIFO principle. This paper presents a developed model that is realized in the following phases: recording data, preparing data for training, training the neuro-fuzzy system, forming a data set for testing where the expected mean service speed is obtained using the moving average method, and testing the neuro-fuzzy model. Observing the mass service system has so far been directed towards, the evaluation of their behaviour in the past which presents a basis to evaluate whether the system provides satisfactory performances. This paper moves a step in the direction of the behaviour evaluation of a mass service system, in the future, in order to observe whether it is possible to predict the service quality level to be provided to a customer. System customer in this case is not limited by the number of demanded services.
\end{abstract}

Keywords: Waiting time; Postal network unit; Financial services; ANFIS

\section{Introduction}

Inspired by the fact that the contemporary research of the mass service systems has been directed towards the system analysis in the past, as well as the significance of the system behaviour in the future and the possible application in the estimated queuing time (for providing the adequate level of service and the 
engagement of the necessary resources), we have decided to apply the combination of all the existing methods to a postal network unit in the Post of Serbia. This paper presents what can be considered an innovative method presenting the combination of the two known methods, ANFIS approach and moving average method. Previous approaches were only based on one method, e.g. on the mass service theory or Monte Carlo method, see [1, 26]. Since the method presented in the paper introduces the combination of the ANFIS approach and the moving average method, we expect that this method or a modification of it will find the application both in other postal units and everywhere else where queuing is a regular phenomenon. In order to realize the mass service system management in the real time, the dataset that trained the model in ANFIS has been modified using the moving average method with the goal to estimate the system behaviour, which can be considered a step forward in comparison to previous research.

Mass service system managers are faced with the issue of providing an optimal relationship between the engaged resources and the time spent by the customer in order to realize their own demands. The satisfaction with the waiting time is not only a determinant for the satisfaction with the service; it also moderates the relation satisfaction - loyalty [6].

The traditional standpoint in the mass service theory is aimed at the optimal determination of the handling channel, where the customer is seen as an external factor. However, more attention is devoted recently to customer behaviour and unification of behavioural aspects, as well as studies dealing with service operations. The impact of waiting on the evaluation of service presents the main focus in numerous papers $[5,9,18,28,31]$.

The question for queue management is not only the real time spent by a customer in a queue, it is also the customer's perception of that time and the related level of their satisfaction with the service [8]. Information on the waiting time has a positive impact on the customer's satisfaction with the waiting time [6].

After the realized service, the customer knows the waiting time spent and they use the experience to adjust their view on the average waiting time in a visited facility. Following it, one can present the customer's degree of satisfaction as a quotient of the acceptable and the expected waiting time based on the previous experience [30]. If a customer is provided with the information on the expected waiting time, their acceptable waiting time will be close to the expected time, since that information would influence the decision whether to approach the system or not at a certain period of time.

The problem that service providers have to deal with and that leads to alternate service quality is observed in the fluctuation of service demands. Solving the problem can lead, in one hand, to the development of more flexible systems (during the peak load additional resources are included), or on the hand, it can influence the customer's motivation by providing more satisfactory service 
realization conditions during low demand periods [6]. Likewise, coordinating demands and capacities will allow for the utilization of diverse strategies for the queue organization, considering their configuration or the formation of a certain ambient, so that waiting can be more interesting and more bearable [34].

When waiting time estimation is considered, the research in call centres has been directed towards queuing in the FIFO system [3, 10, 11, 14, 32].

Services realized by traditional postal operators are characterized by heterogeneity, which is a consequence of different contents of postal items, as well as a wide range of financial services (payments out and payments in from bank accounts, agents work for the benefit of banks, advice on receipts, etc.). The demand for services provided by traditional postal operators has a stochastic character and it cannot be accurately determined since it fluctuates in intensity over time and space. These oscillations regarding service demands hamper technological processes in terms of providing adequate resources for their implementation.

According to the Law on payment transactions [25], the public postal operator in Serbia is allowed, in addition to providing postal services, to provide financial services as well. The banking sector as a competition to the public postal operator in the field of financial services is concentrated mainly on the segment of customers who are creditworthy. It is very important to include the segments of population that are not of interest to the banks. Considering this, the state has the venue for the financial inclusion through the public postal operator. As a consequence, the financial availability is reflected in adjusting prices to the solvency of the population segments that are the target area of the financial inclusion. The prediction of the waiting time in postal network units is of great importance in order to ensure adequate capacity for providing these services. Likewise, in order to offer a higher quality to the financial service beneficiaries, it is essential for them as well to be provided with the information on the queuing time, which is the research topic discussed further in the paper.

The paper is organized in the following manner: second section contains the analysis of the existing conditions in a postal network unit, the third section contains a proposition for a model for waiting time estimation, and the last section provides the conclusion with the directions for future research.

\section{Condition Analysis in a Postal Network Unit}

Data acquisition was conducted by recording queuing in a postal network unit for providing services to customers. The observed postal unit included counters for financial services, as well as counters for the reception and delivery of postal items. The selected postal unit is located in a residential neighbourhood, as well as 
in the area with a wealthy number of diverse contents (green market, shopping mall and school). Accordingly, beneficiaries were both the people living in the area, as well as visitors to the green market, shopping mall, etc. Based on the above, it can be considered that the observed postal unit is a representative unit for providing customer service since it is not focused only on a specific segment of customers and since the users of financial services form a single queue.

The objective of the research refers to the counters for the implementation of financial services, so they were in the focus of the recording. Considering the fact that the volume of financial services is the highest in March and December [22, $23,24]$, the recording was completed in the period of two weeks in December (from December, 6 to December, 18), i.e. the period of 12 working days. Working hours of the post office is from 7:00 am to 7:00 pm on weekdays and from 7:00 am to 2:00 pm on Saturdays. The observed system includes three handling channels, with a single queue and the service carried out according to the FIFO principle. The recording included the number of 5727 system customers. Following the Kendall's notation queuing theory, the system can be classified as $\mathrm{M} / \mathrm{G} / 3$.

Testing the input stream of customers was realized according to days in Statistica 10 (StatSoft software package). An example for the first day is provided in Table 1. It can be observed that the widths of the classes are defined in the periods of 50 seconds. Table column Observed Frequency presents the recording frequencies, while the column Expected Frequency presents the theoretical frequencies of the observed classes for exponential distribution.

Table 1

Testing the compatibility of the input stream with the exponential distribution

\begin{tabular}{|c|c|c|c|c|c|c|c|c|c|}
\hline \multirow[b]{2}{*}{$\begin{array}{l}\text { Upper } \\
\text { Boundary }\end{array}$} & \multicolumn{9}{|c|}{$\begin{array}{l}\text { Variable: Var1, Distribution: Exponential } \\
\text { Chu-Square }=10.11028, \mathrm{df}=5 \text { (adjusted), } \mathrm{p}=\mathbf{0 . 0 7 2 1 7}\end{array}$} \\
\hline & $\begin{array}{l}\text { Observed } \\
\text { Frequency }\end{array}$ & $\begin{array}{l}\text { Cumulative } \\
\text { Observed }\end{array}$ & $\begin{array}{l}\text { Percent } \\
\text { Observed }\end{array}$ & $\begin{array}{l}\text { Cumul.\% } \\
\text { Observed }\end{array}$ & $\begin{array}{l}\text { Expected } \\
\text { Frequnecy }\end{array}$ & $\begin{array}{l}\text { Cumulative } \\
\text { Expected }\end{array}$ & $\begin{array}{l}\text { Percent } \\
\text { Expected }\end{array}$ & \begin{tabular}{l|} 
Cumul.\% \\
Expected
\end{tabular} & $\begin{array}{l}\text { Observed- } \\
\text { Expected }\end{array}$ \\
\hline$<=50.00000$ & 294 & 294 & 53.84615 & \begin{tabular}{|l|}
53.8462 \\
\end{tabular} & \begin{tabular}{|l|}
274.1121 \\
\end{tabular} & \begin{tabular}{|r|}
274.1121 \\
\end{tabular} & 9.194812 & 50.2037 & 19.8879 \\
\hline 100.00000 & 119 & 413 & 21.79487 & 75.6410 & 136.4977 & 410.6098 & 4.578679 & 75.2033 & -17.4977 \\
\hline 150.00000 & 65 & 478 & 11.90476 & 87.5458 & 67.9709 & 478.5806 & 2.280014 & 87.6521 & -2.9709 \\
\hline 200.00000 & 29 & 507 & 5.31136 & 92.8571 & 33.8470 & 512.4276 & 1.135363 & 93.8512 & -4.8470 \\
\hline 250.00000 & 15 & 522 & 2.74725 & 95.6044 & 16.8546 & 529.2822 & 0.565369 & 96.9381 & -1.8546 \\
\hline 300.00000 & 9 & 531 & 1.64835 & 97.2527 & 8.3930 & 537.6751 & 0.281533 & 98.4753 & 0.6070 \\
\hline 350.00000 & 10 & 541 & 1.83150 & 99.0842 & 4.1794 & 541.8545 & 0.140193 & 99.2408 & 5.8206 \\
\hline 400.00000 & 1 & 542 & 0.18315 & 99.2674 & 2.0812 & 543.9357 & 0.069811 & 99.6219 & -1.0812 \\
\hline 450.00000 & 2 & 544 & 0.36630 & 99.6337 & 1.0364 & 544.9721 & 0.034763 & 99.8117 & 0.9636 \\
\hline 500.00000 & 2 & 546 & 0.36630 & 100.0000 & 0.5161 & 545.4881 & 0.017311 & 99.9062 & 1.4839 \\
\hline$<$ Infinity & 0 & 546 & 0.00000 & 100.0000 & 0.5119 & 546.0000 & 0.017170 & 100.0000 & -0.5119 \\
\hline
\end{tabular}

The header of the table presents the values of $\chi^{2}$ test, the number of degrees-offreedom, and the resulting $\mathrm{p}$ - value. Based on the provided p-value of 0.07217 , it can be observed that the distribution of the input stream for the first day corresponds to the exponential distribution at the significance level of 0.05 . Figure 1 , presents graphical interpretations of recorded data for the presented day. 


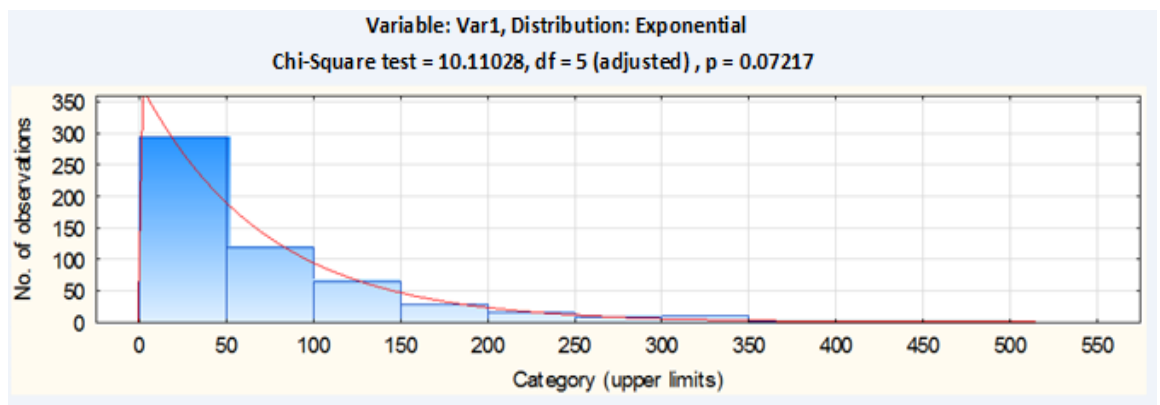

Figure 1

Graphical overview of the input stream of clients during the first day

Investigations were carried out for the remaining days as well, and the results obtained are shown in Table 2. Based on the results shown in Table 2, it can be concluded that the mid-intervals of the input streams of customers (time flow between successive arrivals of customers) during the observed days in nine cases correspond to the exponential distribution with the reliability level of $95 \%$, i.e. pvalues are lower than 0.05 in three cases out of the observed 12 days.

Table 2

p-values of the input streams of customers in testing the compatibility with exponential distribution

\begin{tabular}{|l|c|c|c|c|c|c|c|c|c|c|c|c|}
\hline Days & 1 & 2 & 3 & 4 & 5 & 6 & 7 & 8 & 9 & 10 & 11 & 12 \\
\hline p-values & 0.072 & 0.428 & $<10^{-5 *}$ & 0.23 & 0.12 & $0.015^{*}$ & 0.174 & 0.161 & 0.55 & 0.662 & 0.186 & $2 \cdot 10^{-4 *}$ \\
\hline
\end{tabular}

By integrating the acquired data for the observed period, it is clear that the time intervals of mid-arrivals in the input stream of clients correspond to the exponential distribution with the parameter $\lambda=1.026$ customer $/ \mathrm{min}$, with the reliability level of $95 \%$ (i.e. p-value equals 0.0964 ).

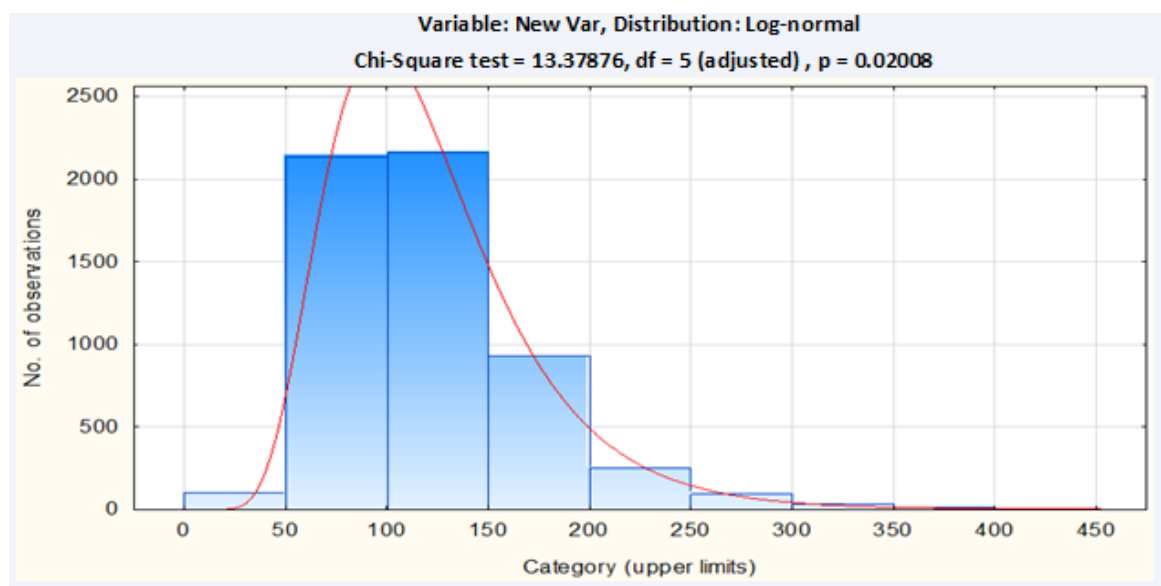

Figure 2

Distribution of service speed for the observed period of 12 days 
After examining the compliance of the input data stream, the next to be tested was the service itself. It was established that the unified service for the observed period tends towards the log-normal distribution with the parameters $a=4.722$ and $b=$ 0.153 (Figure 2), with the reliability level of $99 \%$ since the low p-value of 0.02 was acquired. As for the data acquired for the observed days in 5 cases, after testing the compatibility with the log-normal distribution, it can be observed that the obtained p-values are lower for 0.01 (Table 3), whereas in other cases it can be considered that the service level corresponds to the log-normal distribution.

Table 3

p-values of the input streams of customers in testing the compatibility with log-normal distribution

\begin{tabular}{|l|c|c|c|c|c|c|c|c|c|c|c|c|}
\hline Days & 1 & 2 & 3 & 4 & 5 & 6 & 7 & 8 & 9 & 10 & 11 & 12 \\
\hline p-values & 0.042 & 0.338 & 0.099 & 0.076 & 0.051 & 0.023 & $0.007 *$ & $<10^{-5 *}$ & $<10-4 *$ & $0.001 *$ & 0.027 & $<10^{-5 *}$ \\
\hline
\end{tabular}

We can say that the precise analysis on the system with the form $M / G / n$ is extremely demanding since the non-Markovian processes are happening inside the system, hence the formulas for calculating the system parameters that are widely applied in the cases of, for example, $\mathrm{M} / \mathrm{M} / \mathrm{n}$ systems, cannot be applied in this case. The observed system is characterized by heterogeneity, which is a consequence of different contents of postal items, as well as a wide range of financial services (payments out and payments in from bank accounts, agents work for the benefit of banks, advice on receipts, etc.). The demand for services provided by traditional postal operators has a stochastic character and it cannot be accurately determined since it fluctuates in intensity over time and space. In practice, the most commonly applied analysis is the approximation or simulation (as in the case of call centres [33, 35]). Concerning the observed system, the situation is even more complicated with the number of active handling channels altered during the observed interval. Differently from call centres, postal clerks are in a direct contact with service users and the overall ambient created in the counter hall. As a consequence, the working performances of clerks are exposed to the influence of the phenomenon of congestion which may lead to their working deterioration (clerks' fatigue) or improvement (striving to perform the job better to eliminate the occurrence of congestion). Likewise, the customer's possibility to claim an unlimited number of services further complicated the observance of the system. Considering the complexity of the observed system, i.e. the uncertainty and stochasticity as its properties, the research was focused on the development of a model based on the neuro-fuzzy approach for the evaluation of the waiting time.

\section{Proposition for a Model}

The main results are presented in this section of the paper. It describes the theoretical basis for the model created with ANFIS. After that, there is a proposition for a model for estimating the waiting time. The preparation of data for training ANFIS is realized. Training ANFIS is carried out by the fuzzy logic 
toolbox, Matlab R2007b. It is followed by the data preparation for model testing. The test results are presented by RMSE (root mean square error), the coefficient of determination and the distribution of error values (differences between simulated and recorded values). At the end of this chapter, the average waiting time per each day is observed, as well as the movement of the queue length in selected days.

\subsection{Neuro-Fuzzy Systems}

Different techniques of artificial intelligence have been developed to solve problems of the real world using intelligent systems that possess skills similar to human skills in certain domains. Among them, fuzzy logic and neural networks are the most popular and widely applied in industrial applications $[4,15,16,17$, 20, 21]. Fuzzy logic systems are widely applied in transportation engineering [29].

Adaptive Neuro-Fuzzy Inference System is a multi-layer adaptive network based on the fuzzy inference system [13]. ANFIS is a fuzzy inference system that can be trained on the basis of the acquired input-output data. The training method allows the system to adjust its parameters in order to perceive the input-output relationship hidden in the data set. Since it comprises two approaches (neural networks and fuzzy modelling), the appropriate inference in the quality and the quantity can be achieved [2].

In the case of the Sugeno fuzzy model of the first type with two inputs $x$ and $y$, the rules are given in the following form:

$$
\begin{aligned}
& \text { Rule 1: if } x \text { is } A_{1} \text { and } y \text { is } B_{1} \text { then } f_{1}=p_{1} x+q_{1} y+r_{1} \\
& \text { Rule 2: if } x \text { is } A_{2} \text { and } y \text { is } B_{2} \text { then } f_{2}=p_{2} x+q_{2} y+r_{2}
\end{aligned}
$$

where $A_{1}, A_{2}, B_{1}, B_{2}$ are membership functions for the inputs $x$ and $y$ respectively, whereas $\mathrm{p}_{1}, \mathrm{q}_{1}, \mathrm{r}_{1}, \mathrm{p}_{2}, \mathrm{q}_{2}, \mathrm{r}_{2}$, are the parameters of the output functions [27]. The corresponding ANFIS structure consists of five layers that are implemented by diverse functions of the nodes for training and by adjusting the parameters of a fuzzy system (Figure 3). Nodes located within the same layer have similar functions. The output of the $\mathrm{i}$-th node within the layer 1 can be referred to as $\mathrm{O}_{1, \mathrm{i}}$. The functioning of the presented ANFIS system can be graphically represented as follows [13]:

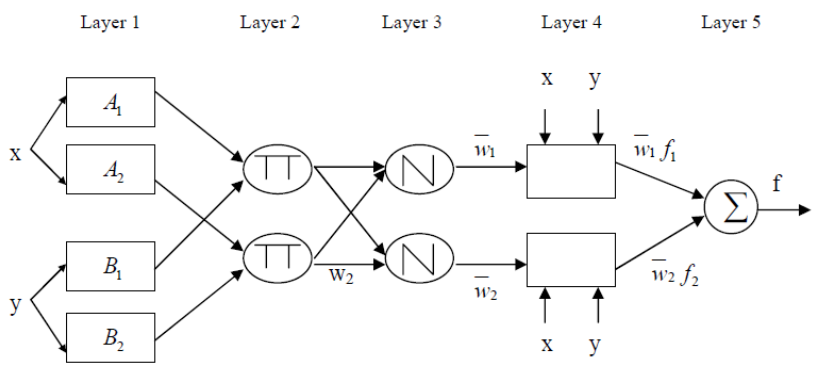

Figure 3

ANFIS architecture of the Sugeno fuzzy model with two inputs [13] 
- Layer 1: The nodes of this layer generate membership functions for input variables. The output of the nodes $\mathrm{O}_{1, \mathrm{i}}$ is defined by the following expressions:

$$
\begin{array}{ll}
\mathrm{O}_{1, \mathrm{i}}=\mu_{\mathrm{A}_{\mathrm{i}}}(\mathrm{x}) & \text { for } \mathrm{i}=1,2 \text { or } \\
\mathrm{O}_{1, \mathrm{i}}=\mu_{\mathrm{B}_{\mathrm{i}-2}}(\mathrm{y}) & \text { for } \mathrm{i}=3,4
\end{array}
$$

where $\mathrm{x}$ and $\mathrm{y}$ are inputs into the node, while $\mathrm{A}_{\mathrm{i}}$ and $\mathrm{B}_{\mathrm{i}}$ are fuzzy sets related to the observed node and are defined by the shape of their membership function. Membership functions $A_{i}$ and $B_{i}$ can be presented by the generalized "bell" function:

$$
\mu_{\mathrm{i}}(\mathrm{x})=\frac{1}{1+\left[\left(\mathrm{x}-\mathrm{c}_{\mathrm{i}}\right) / \mathrm{a}_{\mathrm{i}}\right]^{2 \mathrm{~b}_{\mathrm{i}}}}
$$

where $a_{i}, b_{i}$ and $c_{i}$ are parameters that change the shape of the membership function $\mu_{\mathrm{i}}(\mathrm{x})$ from the minimum value 0 to the maximum value 1 . The parameters of this layer correspond to the parameters of the premise (hypothesis) of the fuzzy model. Outputs of the first layer are values of the membership function of the premise.

- $\quad$ Layer 2: The nodes labelled with $\Pi$ make up the second layer, which means that the input signals in the node are multiplied and the output of the node $\mathrm{O}_{2, i}$ presents a strength of the $\mathrm{i}$-th rule $\mathrm{w}_{i}$ which is calculated as follows:

$$
\mathrm{O}_{2, \mathrm{i}}=\mathrm{w}_{\mathrm{i}}=\mu_{\mathrm{A}_{\mathrm{i}}}(\mathrm{x}) \mu_{\mathrm{B}_{\mathrm{i}}}(\mathrm{y}) \quad \mathrm{i}=1,2
$$

- Layer 3: In this layer the nodes labelled with $\mathrm{N}$ calculate the ratio of the strength of the $\mathrm{i}$-th rule and the sum of strengths of other rules, while the normalized power of the $\mathrm{i}$-th rule is obtained as follows:

$$
\mathrm{O}_{3, \mathrm{i}}=\overline{\mathrm{w}}_{\mathrm{i}}=\frac{\mathrm{w}_{\mathrm{i}}}{\mathrm{w}_{1}+\mathrm{w}_{2}} \quad \mathrm{i}=1,2
$$

- Layer 4: The nodes of the fourth layer calculate the contribution of the i-th rule to the output of the system with the following node function:

$$
\mathrm{O}_{4, \mathrm{i}}=\overline{\mathrm{w}}_{\mathrm{i}} \mathrm{f}_{\mathrm{i}}=\overline{\mathrm{w}}_{\mathrm{i}}\left(\mathrm{p}_{\mathrm{i}} \mathrm{x}+\mathrm{q}_{\mathrm{i}} \mathrm{y}+\mathrm{r}_{\mathrm{i}}\right) \quad \mathrm{i}=1,2
$$

where is the output of the third layer, while a set of parameters $\left(\mathrm{p}_{\mathrm{i}}, \mathrm{q}_{\mathrm{i}}, \mathrm{r}_{\mathrm{i}}\right)$ corresponds to the parameters of consequences.

- Layer 5: This layer consists of one node that is denoted by $\sum$ and calculates the total output of the ANFIS as follows:

$$
\mathrm{O}_{5, \mathrm{i}}=\sum_{\mathrm{i}} \overline{\mathrm{w}}_{\mathrm{i}} \mathrm{f}_{\mathrm{i}}=\frac{\sum_{\mathrm{i}} \mathrm{w}_{\mathrm{i}} \mathrm{f}_{\mathrm{i}}}{\sum_{\mathrm{i}} \mathrm{w}_{\mathrm{i}}}
$$


It may be noted that within the ANFIS architecture there are two adaptive layers, those being the first and the fourth layer. The parameters that are set within the first layer are connected to the input membership function (in the explained example those are parameters $a_{i}, b_{i}$ and $c_{i}$ ), the so-called premise parameters. Within the fourth layer, parameters that are set relate to the first-order polynomial $\left(\mathrm{p}_{\mathrm{i}}, \mathrm{q}_{\mathrm{i}}\right.$ and $\left.\mathrm{r}_{\mathrm{i}}\right)$ and are referred to as consequence parameters $[12,13]$.

Neuro-fuzzy inference system is optimized by adapting the premise parameters and the consequence parameters in a manner as to minimize the defined objective function (most common, the difference between model outputs and actual outputs). The methods for improving the ANFIS parameters may include the gradient descent and Least Square Error (LSE) [13]. Chen (1999) compared the algorithms for training parameters in ANFIS membership functions [7]. The paper applied the hybrid learning algorithm that is a combination of the least square estimation and the back-propagation algorithms [13].

\subsection{Model Development and Results Overview}

Developing the model that is presented in this paper has been implemented through the following stages (Figure 4): recording the mass service systems, creating a data set for training ANFIS, training ANFIS, establishing data for testing, and testing and evaluating the model. During the recording process, the following variables were included: the number of active handling channels, queue length (i.e. number of customers) and the speed of the service level (customer/min). These values are used as inputs to ANFIS.

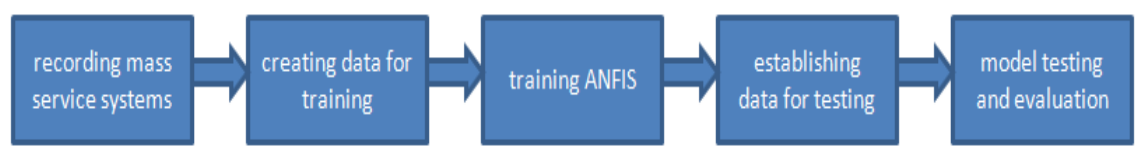

Figure 4

A model for the waiting time estimation

In preparing data for system training, it was necessary to modify the input size of the handling speed. Namely, the problem occurring is reflected in the fact that, when a customer accesses the queue, it is necessary to predict the service speed until the arrival to the service. Regarding this, the decision was to observe the service speed in segments of ten customers, for whom the average service speed was calculated. It was decided not to train the system with data on speed service that was recorded for each customer since in this manner the system would become too "sensitive" to this parameter. In other words, the prediction methods could not provide exact figures of the level obtained at the level of recording. The next phase in the observed model is the system training. The training of the system is realized in the ANFIS Editor GUI, within the software Matlab R2007b. 
Applying the subtractive clustering method, with the default parameter values being the range of influence 0.5 , squash factor 1.25 , accept ratio 0.5 and reject ratio 0.15 , the initial fuzzy training system was formed, i.e. Sugeno fuzzy model with three inputs (Figure 8). Each of the three inputs is associated with two membership functions (Figure 5, 6, 7). Membership functions in Figure 5, are defined by the following parameters: blue $-e^{\frac{-(x-1.068)^{2}}{0.25}}$ and red $-e^{\frac{-(x-2.032)^{2}}{0.2420}}$. Membership functions in Figure 6, are defined by the following parameters: blue $e^{\frac{-(x-0.487)^{2}}{0.0561}}$ and red $-e^{\frac{-(x-0.6041)^{2}}{0.05}}$. A

in Figure 7, are as follows: blue $-e^{\frac{-(x-6.001)^{2}}{76.6322}}$ and red $-e^{\frac{-(x-17)^{2}}{76.5570}}$.

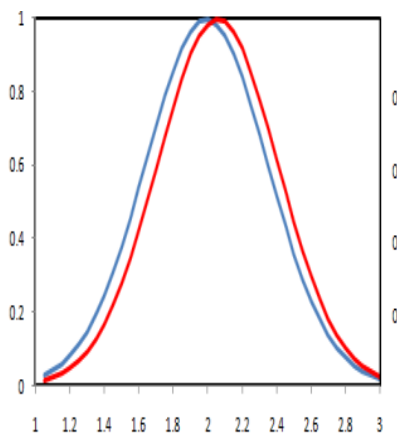

Figure 5

Number of active handling channels

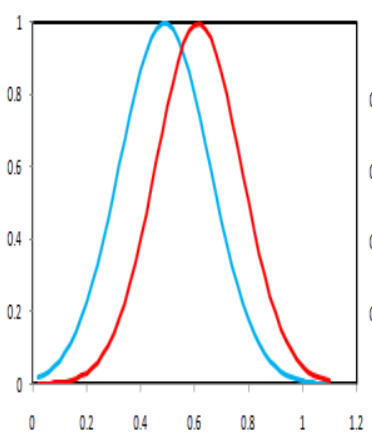

Figure 6 Service speed (customer/min)

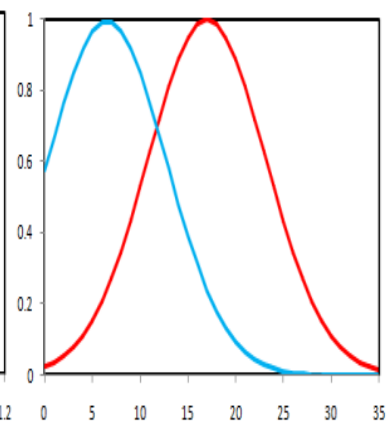

Figure 7

Queue length (number of customers)

The system is defined by the two-rule base, as well as by two output membership functions. The number of epochs for training the system is 300 , while the hybrid algorithm for training is implemented. Features of the system are stabilized after 20 epochs already to the RMSE value of 80 seconds.

Altering the values of the initial set parameters for applying the subtractive clustering method does not bring any significant improvement related to the RMSE, even with the increase in the number of the membership functions (Table 4). In the case of decreasing the value of the range of influence, the number of generated membership functions is increased. A little decrease in RMSE to 77 seconds is observed, though the surface of the transfer function is dramatically disrupted. The similar situation applies to the alteration of other parameters in the direction of increasing the number of the membership functions.

The graphical representation of the transfer function of the obtained system can be observed according to the pairs of input sizes: number of handling channels vs. service speed (Figure 9), number of handling channels vs. queue length (Figure 10), and service speed vs. queue length (Figure 11). A good feature of the obtained surfaces is reflected in the fact that they do not have any peaks, that is, there is a bland transition on changing the input values. 
Table 4

RMSE as parameters in the subtractive clustering method

\begin{tabular}{cccccc}
\hline $\begin{array}{c}\text { range of } \\
\text { influence }\end{array}$ & $\begin{array}{c}\text { squash } \\
\text { factor }\end{array}$ & $\begin{array}{c}\text { accept } \\
\text { ratio }\end{array}$ & $\begin{array}{c}\text { reject } \\
\text { ratio }\end{array}$ & $\begin{array}{c}\text { number } \\
\text { mf }\end{array}$ & RMSE \\
\hline 0.5 & 1.25 & 0.5 & 0.15 & $2+2+2$ & 80.79 \\
0.4 & 1.25 & 0.5 & 0.15 & $3+3+3$ & 81.07 \\
0.3 & 1.25 & 0.5 & 0.15 & $5+5+5$ & 78.91 \\
0.2 & 1.25 & 0.5 & 0.15 & $10+10+10$ & 78.14 \\
0.1 & 1.25 & 0.5 & 0.15 & $33+33+33$ & 77.16 \\
\hline
\end{tabular}

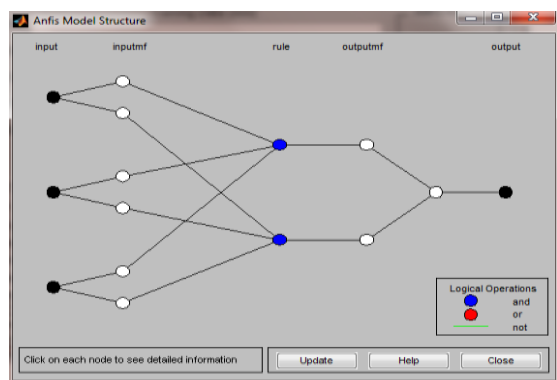

Figure 8

ANFIS structure of the proposed model

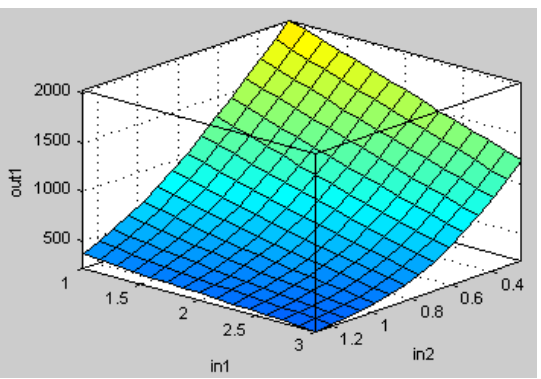

Figure 9

Transition function for the input of handling channels vs. service speed

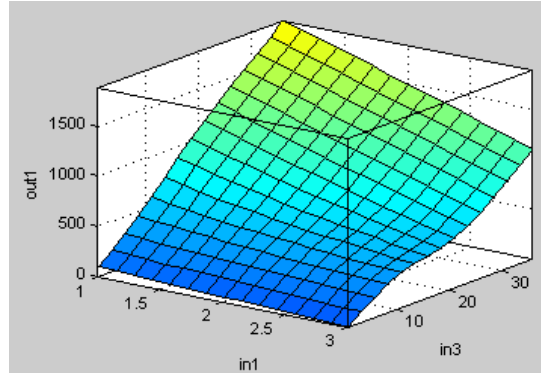

Figure 10

Transition function for the input of handling channels vs. queue length

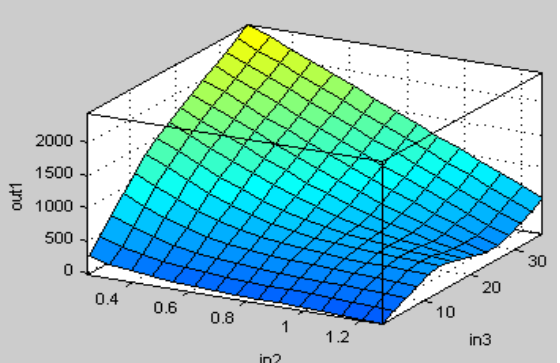

Figure 11

Transition function for the input of service speed vs. queue length

After training the model, a new data set for the system testing was established. In addition to input values, the number of handling channels and the queue length, the value to be estimated was the speed of the handling system when the n-th customer approaches. The estimation of the speed rate was achieved using the simple moving average method, in a manner that the speed from 3 previous intervals of ten recorded data, each was considered. Data set for testing was reduced to 5376 due to the initial segments for the moving average method for each day. 
In order to examine the degree of similarity of the developed model with the recorded conditions in the postal network unit, absolute errors simulated vs recorded were calculated. The distribution of errors is given in Figure 12, where it can be observed that the expected value of the error is 0.451 seconds with a standard deviation of 154 seconds. The level of similarity of the simulated and the recorded data is expressed with the coefficient of determination (Figure 13):

$R^{2}=\left[\frac{\sum\left(S_{r}-\overline{S_{r}}\right)\left(S_{s}-\overline{S_{s}}\right)}{\sqrt{\sum\left(S_{r}-\overline{S_{r}}\right)^{2} \sum\left(S_{s}-\overline{S_{s}}\right)^{2}}}\right]^{2}$

where $S_{\mathrm{r}}$ are the recorded values, while $\mathrm{S}_{\mathrm{s}}$ are simulated values.

In comparison to the data recorded, the simulated data of the represented model have RMSE of 154 seconds and the coefficient of determination with the value of 0.826 .

Likewise, the model simulation was implemented with the moving averages of 4 and 10 intervals, where the results obtained for RMSE were $158 \mathrm{sec}$ and $167 \mathrm{sec}$, while the coefficients of determination were 0.817 and 0.796 , respectively.

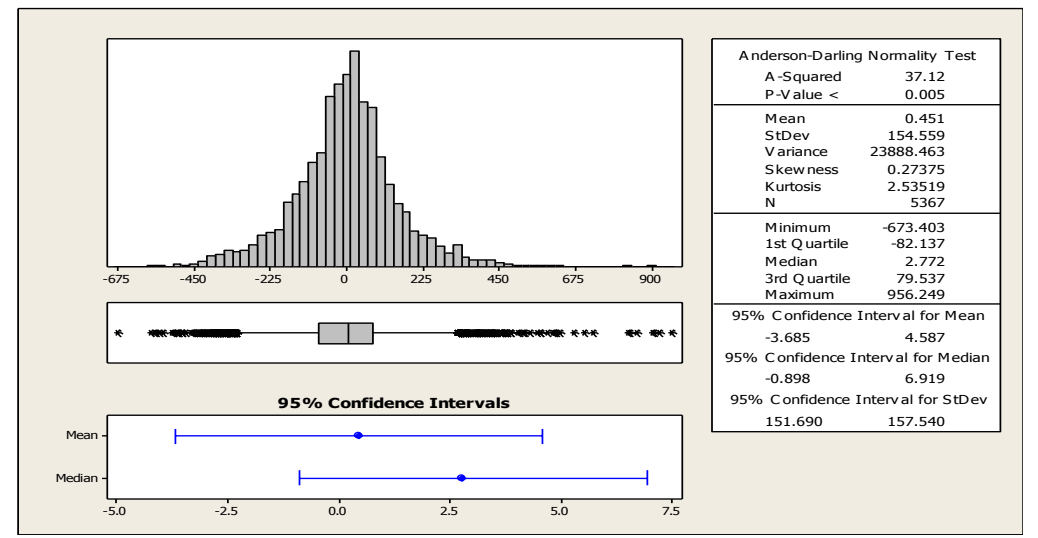

Figure 12

Distribution of the error values in Minitab 16

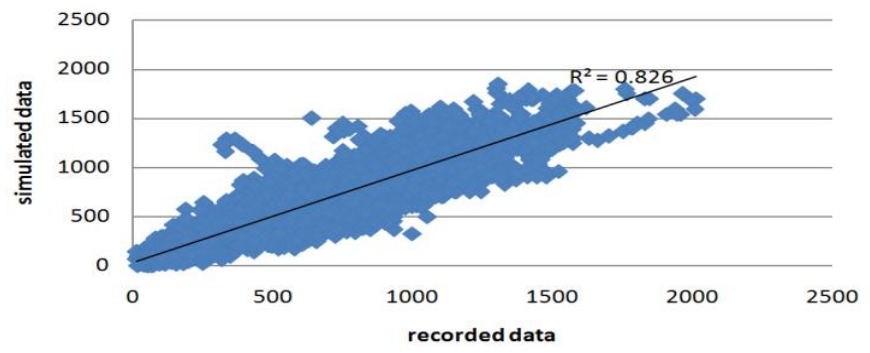

Figure 13

Comparison of recorded values and values obtained in ANFIS 
The model used in the paper is the one with the moving averages from 3 previous intervals. It also possesses the advantage observed in the fact that too much time would not elapse before the model begins the estimation in comparison to the beginning of the working hours in the postal network unit for providing services to customers. Certainly, the sooner the estimation begins, a lower number of unsatisfied customers is to be expected since queuing appears to last longer to a customer with the lack of information on its duration compared to the customer with the known waiting time [19].

In continuation, the average waiting time per day was observed, as well as the values of average waiting times obtained by simulation. Table 5 , provides the ratio of average waiting times that were recorded and average times obtained by simulation, where it can be observed that these values are very similar (maximum deviation is 17 seconds).

The minimum average waiting time of 176 seconds was observed on the fourth day of recording, i.e. in the ninth day of the month when different inquiries influencing the increase in volume of financial services have not yet come to their due dates. During this day, the peaks related to the queue length reached the value of 7 customers at 9:50 and 11:30 in the morning. In the afternoon, the queue length reached a maximum value of 3 customers at 14:00, 15:00 and 18:00.

Table 5

Average waiting times recorded vs. simulated

\begin{tabular}{|c|c|c|c|c|c|c|c|c|c|c|c|c|}
\hline Day & 1 & 2 & 3 & 4 & 5 & 6 & 7 & 8 & 9 & 10 & 11 & 12 \\
\hline $\begin{array}{c}\text { Average waiting } \\
\text { time, } \\
\text { recorded, sec. }\end{array}$ & 367 & 290 & 273 & 176 & 388 & 366 & 680 & 485 & 409 & 645 & 707 & 665 \\
\hline $\begin{array}{c}\text { Average waiting type } \\
\text { of the model, sec. }\end{array}$ & 366 & 293 & 256 & 183 & 389 & 372 & 678 & 490 & 422 & 647 & 700 & 654 \\
\hline
\end{tabular}

The highest average waiting time was observed on the $11^{\text {th }}$ day of recording. The reason for this is reflected in the fact that it was the $17^{\text {th }}$ day of the month when diverse inquiries are due to be paid. Additional impact was caused by the situation that it was the last workday for most customers, and also by the fact that business policies of some companies provide their customers a certain discount for payments before the $20^{\text {th }}$ of the month. The maximum queue length in the morning reached a number of 24 customers at 10:30. In the afternoon, the longest queue was observed at 16:20, with 28 customers. As an average day, there is the $8^{\text {th }}$ day of recording. In the morning, the queue length reached the maximum value of 27 customers at 11:30, while in the afternoon the maximum queue length was with 14 users at 13:45.

\section{Conclusion}

This paper presents a model for estimating the waiting time based on ANFIS. The developed model shows a satisfactory result considering the value of the coefficient of determination $\mathrm{R}^{2}=0.826$, as well as the value of RMSE of 154 
seconds. The average waiting time recorded per day and the average waiting time obtained by the proposed model provide similar results (Table 5). Estimating the service time as the input value required an adequate modification (average value of 10 serving times, as well as the application of the moving average method), so that the proposed model would be more reliable to describe the observed queuing system.

The contribution of the model is in providing information to both the customers and the management of the postal network unit. Providing information on the waiting time presents an additional quality of the service since customers can expect how much of their time to set aside, which makes the waiting process appear acceptable. The same information provides an opportunity for post office managers to manage a number of active counters in real time. In other words, by changing the parameters in the proposed system an adequate simulation can be implemented, which will then indicate whether a particular procedure is justified, i.e. whether the available resources are utilized in an optimal manner.

Further development will be focused on estimating the number of consumers who will ask for a service at specified time intervals and, thus, provide a timely activity in order to try to prevent the congestion of the system. Further considerations may include the number of services to be observed in order to obtain an average speed of service in the observed time interval, as well as the number of sample intervals in estimating the service speed by using the moving average method.

\section{Acknowledgements}

This research is supported by the Ministry of Science of Serbia, Grant Numbers 36040, 174009, 32035.

\section{References}

[1] I. Adan, J. Resing, Queueing theory, Dept. of Mathematics and Computing Science, Eindhoven University of Technology, Netherlands, 2002

[2] M. Alizadeh, F. Jolai, M. Aminnayeri, R. Rada, Comparison of Different Input Selection Algorithms in Neuro-Fuzzy Modeling, Expert Systems with Applications, 39(1), 1536-1544, 2012

[3] M. Armony, C. Maglaras, Contact Centers with a Call-Back Option and Real-Time Delay Information, Operations Research, 52(4), 527-545, 2004

[4] G. Athanasopoulos, C. R. Riba, C. Athanasopoulou, A Decision Support System for Coating Selection Based on Fuzzy Logic and Multi-Criteria Decision Making, Expert Systems with Applications, 36(8), 10848-10853, 2009

[5] J. Baker, M. Cameron, The Effects of the Service Environment on Affect and Consumer Perception of Waiting Time: an Integrative Review and Research Propositions, Journal of the Academy of Marketing Science, 24(4), 338-349, 1996 
[6] F. Bielen, N. Demoulin, Waiting Time Influence on the SatisfactionLoyalty Relationship in Service, Managing Service Quality, 17(2), 174193, 2007

[7] M. S. Chen, A Comparative Study of Learning Methods in Tuning Parameters of Fuzzy Membership Functions, In Systems, Man, and Cybernetics, 1999 IEEE SMC'99 Conference Proceedings. 1999 IEEE International Conference on (Vol. 3, pp. 40-44) IEEE, 1999

[8] M. M. Davis, J. Heineke, Understanding the Roles of the Customer and the Operation for Better Queue Management, International Journal of Operations \& Production Management, 14(5), 21-34, 1994

[9] M. K. Hui, D. K. Tse, What to Tell Consumers in Waits of Different Lengths: An Integrative Model of Service Evaluation, Journal of Marketing, 60, 81-90

[10] R. Ibrahim, W. Whitt, Real-Time Delay Estimation Based on Delay History, Manufacturing \& Service Operations Management, 11(3), 397415, 2009

[11] R. Ibrahim, W. Whitt, Wait-Time Predictors for Customer Service Systems with Time-Varying Demand and Capacity, Operations Research, 59(5), 1106-1118, 2011

[12] J. S. Jang, Self-Learning Fuzzy Controllers Based on Temporal Back Propagation, Neural Networks, IEEE Transactions on, 3(5), 714-723, 1992

[13] J. S. Jang, ANFIS: Adaptive-Network-based Fuzzy Inference System, Systems, Man and Cybernetics, IEEE Transactions on, 23(3) 665-685, 1993

[14] O. Jouini, Z. Aksin, Y. Dallery, Call Centers with Delay Information: Models and Insights. Manufacturing \& Service Operations Management, 13(4), 534-548, 2011

[15] C. Kahraman, S. Çevik, N. Y. Ates, M. Gülbay, Fuzzy Multi-Criteria Evaluation of Industrial Robotic Systems. Computers \& Industrial Engineering, 52(4), 414-433, 2007

[16] J. Liebowitz, The Dynamics of Decision Support System and Expert System, Orlando: The Dryden Press, 1990

[17] J. Liebowitz, D. A. DeSalvo, Expert Systems for Business and Management, Yourdon Press, 1989

[18] W. J. Luo, M. L. Liberatore, R. B. Nydick, Q. Chung, E. Sloane, Impact of Process Change on Customer Perception of Waiting Time: a Field Study, Omega, 32(1), 77-83, 2004

[19] D. H. Maister, The Psychology of Waiting Lines (pp. 71-78) Harvard Business School, 1984

[20] J. Mendes, R. Araújo, F. Souza, Adaptive Fuzzy Identification and Predictive Control for Industrial Processes, Expert Systems with Applications, 40(17), 6964-6975, 2013 
[21] M. Paliwal, U. A. Kumar, Neural Networks and Statistical Techniques: A Review of Applications, Expert Systems with Applications, 36(1), 2-17, 2009

[22] Post Serbia, Company Profile 2009, available at: http://www.posta.rs/d okumenta/eng/o-nama/profil-preduzeca/Company\%20Profile\%202009.pdf 2010

[23] Post Serbia, PTT glasnik, available at: http://www. posta.rs /dokumenta /PTTglasnik/Postanski\%20glasnik\%20specijal\%20\%20april\%202011.pdf, 2011

[24] Post Serbia, Company Profile 2011, available at: http://www.posta.rs/ dokumenta/eng/o-nama/profilpreduzeca/Company\%20Profile\%202011.pdf, 2012

[25] Republic Serbia, Law on Payment Transactions, FRY Official Gazette, Nos 3/2002 and 5/2003, and RS Official Gazette, Nos 43/2004, 62/2006 and $31 / 2011$

[26] R. Y. Rubinstein, D. P. Kroese, Simulation and the Monte Carlo Method (Vol. 707) John Wiley \& Sons, 2011

[27] T. Takagi, M. Sugeno, Fuzzy Identification of Systems and its Applications to Modeling and Control, Systems, Man and Cybernetics, IEEE Transactions on, (1) 116-132, 1985

[28] S. Taylor, Waiting for Service: the Relationship between Delays and Evaluations of Service, The Journal of Marketing, 56-69, 1994

[29] D. Teodorović, Fuzzy Logic Systems for Transportation Engineering: the State of the Art. Transportation Research Part A: Policy and Practice, 33(5), 337-364, 1999

[30] A. van Ackere, C. Haxholdt, E. R. Larsen, Dynamic Capacity Adjustments with Reactive Customers. Omega, 41(4), 689-705, 2013

[31] A. Whiting, N. Donthu, Managing Voice-to-Voice Encounters Reducing the Agony of Being Put on Hold, Journal of Service Research, 8(3), 234244, 2006

[32] W. Whitt, Predicting Queueing Delays, Management Science, 45(6), 870888, 1999

[33] W. Whitt, Engineering Solution of a Basic Call-Center Model. Management Science, 51(2), 221-235, 2005

[34] V. Zeithaml, J. Bitner, Services Marketing: Integrating Customer Focus across the Firm, $3^{\text {rd }}$ ed., McGraw-Hill Higher Education, New York, 2002

[35] S. Zeltyn, A. Mandelbaum, Call Centers with Impatient Customers: ManyServer Asymptotics of the M/M/n+ G Queue. Queueing Systems, 51(3-4), 361-402, 2005 